\title{
Effect of Sintering Pressure on Microstructure and Properties of Ti/TiC/C Laminated Composites
}

\author{
Wenyuan Long ${ }^{1, a}$, Fan $\mathrm{Wu}^{2, b}$ \\ School of Aeronautical Manufacturing Engineering,Nanchang Hangkong University,Nanchang \\ China,330063 \\ along_weny@sohu.com, b591302810@qq.com
}

Keywords: Spark Plasma Sintering; Laminated Material; Toughening Mechanism.

Abstract. The laminated structure of the $\mathrm{Ti} / \mathrm{C}$ composite materials with sheet of $\mathrm{Ti}$ and $\mathrm{C}$ as raw materials was prepared by spark plasma sintering (SPS) technology. The effects of sintering pressure on the interface characteristics and mechanical properties of interfacial reaction were studied. The results show that: the layer thickness increased with the sintering pressure. When the sintering pressure reached $20 \mathrm{MPa}$, The layer thickness was up to the maximum $34.41 \mu \mathrm{m}$, the laminated composite bending strength and fracture power have the maximum $3939.19 \mathrm{MPa}$ and $540.16 \times 103$ $\mathrm{J} / \mathrm{m}^{2}$, respectively. Bending strength and fracture power of $\mathrm{Ti} / \mathrm{C}$ laminate material is mainly determined by the thickness of metal $\mathrm{Ti}$ layer and the reaction layer of $\mathrm{TiC}$, and the main strength of the laminated composites is the strength of the matrix layers and the strength of the interface reaction layer of a common decision.

\section{Introduction}

Biomimetic design has attracted considerable attention in the international material community because it has achieved significant advances within a short period ${ }^{[1]}$. In the mid-1980s, Professor H. M. Burtle proposed the theme, "The Potential Impact of Biotechnology on Composite Materials." Laminated materials present an important area in air force research ${ }^{[2]}$. Laminated composites have attracted increasing attention for their potential applications in structural components and electronic devices, as well as in the aerospace, automobile, and armor industries ${ }^{[3,4]}$. Typical laminated composites, such as ceramic-ceramic, metal-ceramic, metal-metal, and metal-ceramic-intermetallic systems, have exhibited desirable properties ${ }^{[5,6]}$. These systems can combine the superior ductility and toughness of the softer phase with the high strength and hardness of the harder phase, which leads to the outstanding strength, toughness, and ductility of multilayered composites ${ }^{[7]}$. Several processing techniques, such as adhesion bonding, chemical deposition, diffusion welding, hot accumulative rolling, flake powder metallurgy, and reactive sintering, are used to fabricate these laminated systems ${ }^{[8]}$.

In 1990, Dr. Clegg ${ }^{[9]}$ fabricated SiC/graphite laminated composite material and increased the fracture power of $\mathrm{SiC}$ by a hundredfold by using graphite as the soft layer. Kovar et al. ${ }^{[10]}$ examined the relationship between $\mathrm{BN}$ soft layer properties and the performance of $\mathrm{Si}_{3} \mathrm{~N}_{4} / \mathrm{BN}$ laminated composite material. $\mathrm{Si}_{3} \mathrm{~N}_{4}$ was added into $\mathrm{BN}$ to adjust the fracture toughness of the soft layer and to prepare the $\mathrm{Si}_{3} \mathrm{~N}_{4} / \mathrm{BN}+\mathrm{Si}_{3} \mathrm{~N}_{4}$ laminated composites. Jun Wan ${ }^{[11]}$ examined the properties of new types of $\mathrm{TiC}$ composites and performed vacuum sintering without press technology to fabricate high-volume TiC composites using ultra-fine titanium carbide and cast iron powder of raw materials, which demonstrated favorable metallurgical bonding.

Titanium alloy has a high specific strength, specific stiffness, and temperature durability. Therefore, this material has potential applications in the aerospace, weapons, and automobile industries $^{[12-14]}$. However, such applications are limited because of the low ductility and high brittleness of titanium alloy ${ }^{[15]}$. The use of biomimetic laminated composite materials has introduced major changes. The current study aims to use the advanced SPS technology to fabricate laminated composites, evaluate their mechanical properties, and control their thickness by precisely controlling the thickness of the reaction layer. The microstructure morphology and mechanical properties of the prepared laminate are analyzed at room temperature. 


\section{Experimental}

In this experiment, a $0.5 \mathrm{~mm}$-thick (99\%) titanium film from Alfa Aesar Company was used as the raw material and a $0.2 \mathrm{~mm}$-thick graphite (C) paper was used as the carbon source. First, Ti and $\mathrm{C}$ films were ground and sheared into diameters of $\$ 20 \mathrm{~mm} \times 0.2 \mathrm{~mm}$ and $\$ 20 \mathrm{~mm} \times 0.1 \mathrm{~mm}$, respectively. The Ti films were pretreated in the following sequence: acetone degreasing - distilled water - grinding - mechanical polishing to mirror - acid - ethanol ultrasonic cleaning. The treated $\mathrm{Ti}$ film was then placed into the graphite model along with the $\mathrm{C}$ paper by alternately shearing and sintering in the SPS furnace. Ar was used in the reaction process to prevent the high-temperature sintering of titanium oxide. Table 1 shows the experiment scheme.

Table 1 Sintering of the sample at different sintering pressures

\begin{tabular}{cccccc}
\hline $\begin{array}{c}\text { Sample } \\
\text { no. }\end{array}$ & $\begin{array}{c}\text { Thickness of } \\
\text { Ti } / \mathrm{mm}\end{array}$ & $\begin{array}{c}\text { Thickness } \\
\text { of C/mm }\end{array}$ & $\begin{array}{c}\text { Thickness } \\
\text { ratio }\end{array}$ & $\begin{array}{c}\text { Sintering } \\
\text { temperature/ } \\
\text { C }\end{array}$ & $\begin{array}{c}\text { Sintering } \\
\text { pressure/MPa }\end{array}$ \\
\hline $\mathrm{a}$ & 0.28 & 0.08 & $3.5: 1$ & 1500 & 15 \\
$\mathrm{~b}$ & 0.28 & 0.08 & $3.5: 1$ & 1500 & 20 \\
$\mathrm{c}$ & 0.28 & 0.08 & $3.5: 1$ & 1500 & 25 \\
\hline
\end{tabular}

\section{Results and Discussion}

\section{Structural characteristics of the Ti/C laminated composite}

Fig. 1 shows the macro-shape appearance of the Ti/C laminate at different sintering pressures. The microstructure morphology of the $\mathrm{Ti} / \mathrm{C}$ laminated composite exhibits evident layered structure characteristics after sintering, with each layer having an obvious interface. A combination reaction occurs on the interface of $\mathrm{Ti} / \mathrm{C}$ to form $\mathrm{TiC}$, which can be analyzed based on the phase composition of the interfacial reaction layer of the sample Ti film after sintering. Fig. 2 shows that the main phase compositions of the $\mathrm{Ti}$ film interfacial reaction layer are $\mathrm{C}$ and $\mathrm{TiC}$. With the other conditions unchanged and with an increasing sintering pressure, the thickness of the $\mathrm{C}$ layer demonstrates a decreasing trend. A high pressure will induce the compression thinning of the Ti and $\mathrm{C}$ layers. The $\mathrm{C}$ layer will diffuse into the Ti layer, and the thickness of the $\mathrm{C}$ layer will be relatively reduced.

Fig. 2 shows the X-ray diffraction (XRD) patterns of the interfacial reaction layer of the Ti film at different interface pressures. Phase composition changes along with increasing sintering pressure. The main phase components on the interface reaction of the Ti film are $\mathrm{C}$ and $\mathrm{TiC}$. The diffraction peak of the reaction product of $\mathrm{TiC}$ demonstrates an obscure strengthening trend along with increasing pressure. The content of $\mathrm{TiC}$ does not significantly change when sintering pressure reaches or exceeds $20 \mathrm{MPa}$. Therefore, a sintering pressure of $20 \mathrm{MPa}$ can satisfy the requirement of the experiments.
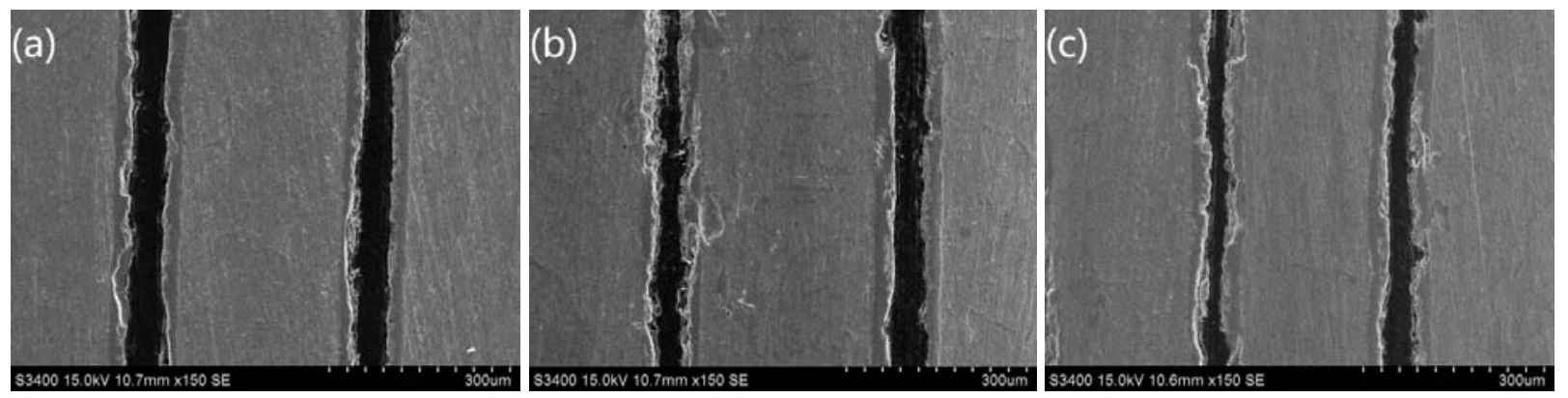

Fig. 1. Apparent morphology of the $\mathrm{Ti} / \mathrm{C}$ laminated interface reaction layer 


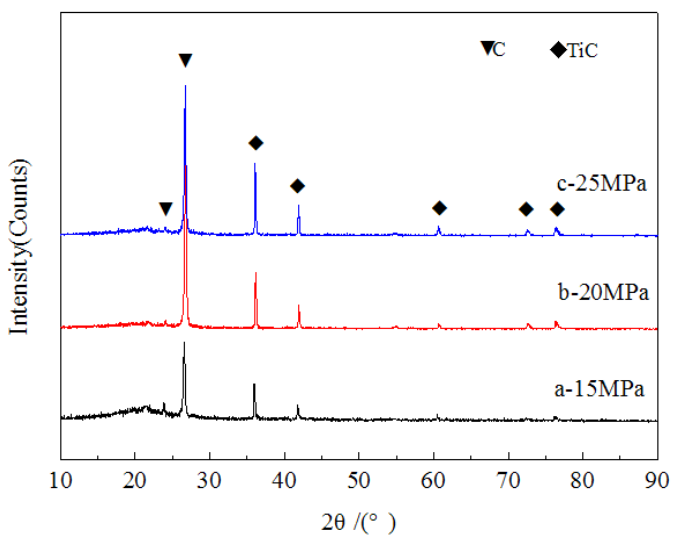

Table 2. Thickness of the interfacial reaction layer at different sintering pressures

\begin{tabular}{cccc}
\hline No. & $\begin{array}{c}\text { Sintering } \\
\text { temperature } /{ }^{\circ} \mathrm{C}\end{array}$ & $\begin{array}{c}\text { Sintering } \\
\text { pressure/MPa }\end{array}$ & $\begin{array}{c}\text { Thickness } \\
/ \mu \mathrm{m}\end{array}$ \\
\hline $\mathrm{a}$ & 1500 & 15 & 24.62 \\
$\mathrm{~b}$ & 1500 & 20 & 34.41 \\
$\mathrm{c}$ & 1500 & 25 & 32.38 \\
\hline
\end{tabular}

Fig. 2. XRD diagrams of the samples at different sintering temperatures

The variation in the thickness of the Ti/C laminated composite interface reaction layer at different sintering pressures is determined as shown in Table 2 . The reactions of the interface are strengthened with the increased sintering pressure. The diffusion reaction layer also demonstrates a thickening trend, with its thickness value increasing from $24.62 \mu \mathrm{m}$ to $34.41 \mu \mathrm{m}$. The thickness of the reaction layer no longer increases when pressure reaches $25 \mathrm{MPa}$ because an extremely high pressure will deform the matrix sample under such process conditions.

\section{Mechanical properties of the laminated material}

Fig. 4 shows that the relationship between the bending strength and changes in the fracture power of the Ti/C laminated material along with sintering pressure. The bending strength of the $\mathrm{Ti} / \mathrm{C}$ laminated material initially increases and then decreases as sintering pressure increases from $15 \mathrm{MPa}$ to $25 \mathrm{MPa}$. The bending strength of the laminated material peaks at $3939.19 \mathrm{MPa}$ when sintering pressure reaches $20 \mathrm{MPa}$.

Fig. 5 presents a sample matrix layer, shows the thickness ratio of the interface reaction layer, and demonstrates the relationship between $\mathrm{Ti} / \mathrm{TiC}$ ratio and sintering pressure. $\mathrm{The} \mathrm{Ti} / \mathrm{TiC}$ ratio initially decreases and then increases along with increasing sintering pressure. Although the thickness of the metal $\mathrm{Ti}$ layer remains the same, the reaction layer thickness of $\mathrm{TiC}$ varies. The $\mathrm{Ti} / \mathrm{TiC}$ ratio presents a minimum value of 8.14 when sintering pressure increases to $20 \mathrm{MPa}$. TiC has the thickest layer at this point, the matrix layer maintains a constant thickness, and the volume percentage of the reaction layer in the material is increased to its maximum value, which in turn, causes the material to reach its maximum bending strength. When pressure is increased to $25 \mathrm{MPa}$, the $\mathrm{C}$ layer is extruded and leads to a partial fracture. Meanwhile, the Ti layers on the top and bottom hang together, the matrix layer becomes thicker, and the volume percentage of the base layer in the material is increased, which in turn, increases material bending strength considerably further than that achieved at $15 \mathrm{MPa}$. The fracture power of the $\mathrm{Ti} / \mathrm{C}$ laminate initially increases and then decreases along with increasing sintering pressure. The comparative analysis shows that the maximum fracture power of $540.16 \times 103$ $\mathrm{J} / \mathrm{m}^{2}$ is achieved when sintering pressure reaches $20 \mathrm{MPa}$. The changes in fracture power and bending strength of the laminated composite materials demonstrate the same trend, which can be explained by the changes shown in Fig.5. Therefore, the bending strength and fracture power of the $\mathrm{Ti} / \mathrm{C}$ laminated material are mainly determined by the thickness of the metal Ti layer and the reaction layer of $\mathrm{TiC}$. 


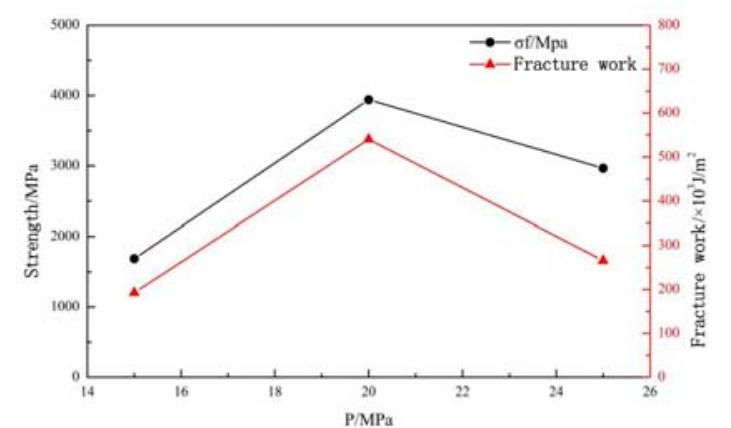

Fig. 4. Changes in mechanical properties along with sintering pressure

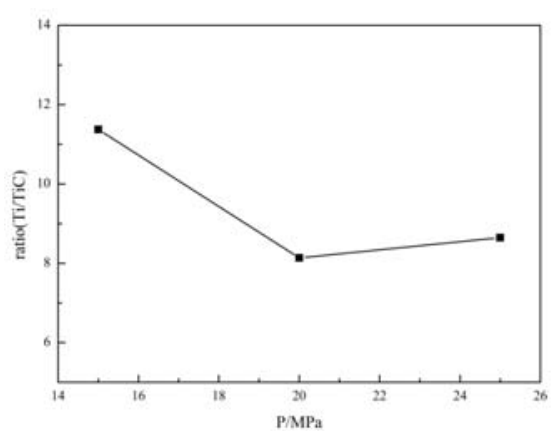

Fig. 5. Changing relation between $\mathrm{Ti} / \mathrm{TiC}$ ratio and pressure

\section{Conclusions}

(1) Ti/C laminated composite materials are prepared using the SPS technology. The degree of interfacial reaction is related to sintering pressure. When sintering pressure reaches $20 \mathrm{MPa}$, the degree of interfacial reaction is improved and layer thickness reaches $34.41 \mu \mathrm{m}$.

(2) When sintering pressure reaches $20 \mathrm{MPa}$, the bending strength and fracture power of the laminated composite peak at $3939.19 \mathrm{MPa}$ and $540.16 \times 103 \mathrm{~J} / \mathrm{m}^{2}$, respectively. Again, the experiment proves that the fracture mode of the laminated composite is breaking layer by layer, which significantly improves the safety and reliability of these materials.

\section{References}

[1] H. Yong, C.W. Li, C.A. Wang, et al. Materials Review. 2000, (8): 8-11.

[2] C.T. Xiang, J.H. Fan: Advances in mechanics. 1994, (2): 220-231.

[3] B.X. Liu, L.J. Huang, L. Geng, et al. Mater. Sci. Eng. A 583(2013), 182-187.

[4] S. Ohsaki, S. Kato, N. Tsuji, Acta Mater. 55(2007) 2885-2895.

[5] RM.P. Rao, Science 286 (1999)102-105.

[6] PY.J. Guo, G.J. Qian, W.Z. Jian, X.H. Zhi, Mater. Sci. Eng. A 527 (2010)5234-5240.

[7] C.M. Cepeda-Jimenez, F. Carreno, O.A. Ruano, et al. Mater. Sci. Eng. A, 563(2013) 28-35.

[8] S. Nambu, M. Michiuchi, J. Inoue, K. Koseki, Compos. Sci. Technol. 69(2009) 1936-1941.

[9] Cleeg W J, Letters to Nature[J], Nature, 1990,347(4):455.

[10]Desidero Kovar, Thouless M D, John W Halloran. J. Am Ceram soc, 1997, 80(3):673-679.

[11]W. Jun, Chang'an University, 2009, 5.

[12]J. Cook, J.E. Gordon, Proc. R. Soc. Lond, 282(1964), 508-520.

[13]C.J. Zhang, F.T. Kong, S.L. Xiao, H.Z. Niu, Y.Y. Chen, Mater. Des. 36(2012) 505-510.

[14]L.J. Huang, F.Y. Yang, H.T. Hu, X.D. Rong, L. Geng, L.Z. Wu, Mater. Des. 51(2013) 421-426.

[15]K.B.Panda, K.S. Ravichandran, Metall. Mater. Trans. A34(2003), 1993-2003. 